\title{
CORRESPONDENCE
}

Early diagnosis of cancer in the head and neck

R B Bradshaw, FRCs, and others.

Liquor licensing and public health

B N C Prichard, MRCP..............956

The North Sea

J W Taylor, MrcGr. . . . . . . . . . . . . . 957

Renal lesions in a case of septicaemia

M F Dixon, MrcPATH. . . . . . . . . . . 957

Sociological realities

J D Scobie, MB, and Rosemary Yale; J R

Mathers, FRCPSYCH.............957

Uterine hypertonus after induction

of labour with prostaglandin $E_{2}$ tablets

$M$ Thiery, MD, and J J Amy, MD........958

Effect of posture on dental anaesthetic mortality

I Curson, FDS, and M P Coplans, FFARCS. .958

Pseudomonas aeruginosa in hospital pharmacies

D C Shanson, MRCPATH; R B Smith, MD . . .9958
Supervision of repeat prescribing

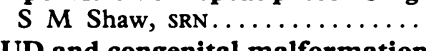

UD and congenital malformat

P C Leighton, FRCSED, and others . . . . . . . 959

Pets in hospitals

A J Macdonald, DPM; D MacCarthy, FRCP . . 959

M Segal, MRCPSYCH. . . . . . . . . . . . . 960

Osteomalacia and calcium deficiency

G F Taylor, MRCP................960

Geriatrics in the cottage hospital

A N Crowther, BM..............960

Domiciliary oxygen in chronic bronchitis

E L Head. . . . . . . . . . . . . . . . . . 960

Computer-held medical records

P R V Tomson, FRCGP; R McG Harden, MD,

and K A Harden, MB............960

Recurrent haematuria

P H O'Reilly, fRcs...............961

Propranolol and the nephrotic syndrome

M J Farr, MRCP.............. 961
Bottle-feeding and tummy-ache in infants

D L J Freed, MB . ................96 Amoebic meningoencephalitis in Britain

D C Warhurst, PHD, and others . . . . . . . 961 Squints

P A Gardiner, MD; A G Carroll, MRCPSYCH . .962 Occupational hazard in preparation of polyacrylamide gels

R A Klein, MB . . . . . . . . . . . . . . . . . .962

Steroids and hypostatic eczema

K Haeger, MD ................ 962

Occult perforations

B K Mandal, MRCPED, and P F Schofield,

FRCS ........................963

Specialist training

M D A Vickers, fFaRcs............963

Future of private practice

C P Wallace, мв. . . . . . . . . . . . .963

Compulsory vocational training

M H A Martin-Smith, MB, and others.....963

BMA and HCSA

N A Simmons, MRCPATH..........963
Correspondents are urged to write briefly so that readers may be offered as wide a selection of letters as possible. So many are being received that the omission of some is inevitable. Letters should be signed personally by all their authors.

\section{Early diagnosis of cancer in the head and neck}

SIR,-We heartily endorse the pleas of $\mathrm{Mr}$ H J Shaw (14 February, p 379) and Professor D F N Harrison (13 March, p 646) for a multi-disciplinary approach to head and neck tumours. However, we are concerned lest Professor Harrison's remarks lead your readers to believe that expertise is so scarce that most patients with head and neck cancer must travel great distances to obtain the treatment that will give them the best chance of cure.

Joint consultation clinics are held in nearly all teaching centres and in many non-teaching hospitals. Our clinic in Cardiff is a fairly typical example; the disciplines of otolaryngology, oral surgery, reconstructive surgery, and radiotherapy are represented. Jointly we see approximately 150 new patients with head and neck cancer annually. We do not practise "surgery by committee." The individual member of our group to whom the patient is

\section{Liquor licensing and public health}

SIR,-Anyone concerned with the limitation of the adverse effects of drugs can only view with misgiving the introduction of a private member's Bill to increase licensing hours and to allow children into public houses. Your timely leading article on the subject (14 February, p 359) must be applauded; I have already had occasion to sound a similar warning note. ${ }^{1}$

The principle that adverse effects to a given drug are proportional to its use and their increased availability leads to increased use (or abuse, or adverse reaction) is generally widely initially referred retains responsibility for that patient. He seeks the help and guidance of the other disciplines to decide upon and carry out an agreed policy. In this way confusion is avoided rather than created. Of the qualities Professor Harrison advocates, skill is subjective; but there is no evidence that in experience, equipment, or results, clinics such as ours are inferior to the more publicised centres.

Certainly the patient with head and neck cancer should be referred to a unit with special interest and experience. There is probably one near at hand.

R B BRADSHAW Michael Green

I P GRIFFITHS

J M HENK

$S$ H RICHARDS University Hospital of Wales,
Cardiff

A B THOMAS

accepted. However, when ethyl alcohol is considered this seems less readily acknowledged. Is this justified as, assuming concern for the health and well-being of the public, supporters of the present Bill appear to believe ? It would seem that the onus is on those who wish to increase the availability of alcohol to prove that alcohol is an exception.

Evidence appears to be to the contrary. Firstly, there is much information showing that consumption of alcohol is correlated with the incidence of alcoholism. ${ }^{2-4}$ Secondly, it appears from "experi- ments" performed for a number of reasons that increase or decrease of alcohol consumption in the community causes the incidence of adverse effects to alcohol rise or fall. With the introduction of wine rationing in Paris in the last war annual mortality from cirrhosis of the liver fell rapidly from around 35 to 6 per 100000 , then quickly resumed its previous level at the end of rationing. ${ }^{3}$ Whatever the problems and failures of prohibition in the US, during that period the cirrhosis death rate fell from 11-15 to 7-8 per 100000 , only to resume its previous level after the end of prohibition. ${ }^{5} \mathrm{Dr} \mathrm{M} M$ Glatt (27 March, p 768) has again pointed out the effect of restricting licensing hours in the UK during the first world war in reducing alcoholism. ${ }^{6}$

Those who can believe that increasing drug availability, either through the number of outlets or the time that they are open, or teaching children to drink in the home will not lead to an increase in consumption should take a long, hard look at France. Here there is wide availability in hours, outlets, and cheapness and it is the cultural norm for children to be trained to drink in the home. France is top of the world in alcohol consumption and the alcoholism league, around 12 times the UK rate. ${ }^{7}$ Already there is recent suggestive evidence that increase in drug availability in the UK through supermarkets is having its first predictable effect-that is, increased acute toxicity, particularly among women.

I hope our legislators will read the recent WHO report $^{7}$ which concluded that it was time that measures were taken to reduce alcohol consumption-for instance, by elimination of mass media advertising. In view of the parlous state of the economy they perhaps ought to reflect on the cost of alcohol consumption to industrial production ${ }^{9}$ and the cost of alcohol-induced disease to the health services, said to be $40 \%$ of the total costs in France. ${ }^{7}$ With all the excitement about the drug bill to the NHS in some quarters it is pertinent to point out therefore that in some countries the cost of health problems induced by this one drug, alcohol, exceeds the cost of all drugs used for therapeutic purposes. Do our legislators wish to try to emulate this in 